\title{
THE INFLUENCE OF CLIMATIC FACTORS ON THE AROMA COMPOUNDS OF FETEASCA REGALA WINE FROM THREE SOUTHERN REGIONS OF ROMANIA
}

\author{
DIANA IONELA STEGARUS ${ }^{a, *}$, DANIELA SANDRU ${ }^{\mathrm{b}}$, PETRU ALEXE $^{\mathrm{c}}$, \\ ADINA FRUM ${ }^{d}$, OANA BOTORAN ${ }^{a}$, ECATERINA LENGYEL ${ }^{b}$
}

\begin{abstract}
Climatic factors have a great influence on the quality of grapes and wines, thus the identification and quantification of aroma compounds from Feteasca regala wine manufactured in 2019 in three established winemaking centers from Romania (Samburesti, Corcova and Dragasani) was performed. After liquid/liquid extraction, the aromatic composition was identified and quantified by gas chromatography coupled with mass spectrometry (GC-MS). 42 aroma compounds were analyzed depending on the region of origin of the vineyards and climatic factors. Results showed significant differences between the wines regions of origin. The quantities of long-chain alcohols varied between $28644.54 \mu \mathrm{g} / \mathrm{L}$ and $33969.27 \mu \mathrm{g} / \mathrm{L}$ and esters between $4221.10 \mu \mathrm{g} / \mathrm{L}$ and $7901.25 \mu \mathrm{g} / \mathrm{L}$. Significant quantities were determined for fatty acids and ranged between $5310.99 \mu \mathrm{g} / \mathrm{L}$ and 6045.15 $\mu \mathrm{g} / \mathrm{L}$ and lactones between $727.39 \mu \mathrm{g} / \mathrm{L}$ and $988.01 \mu \mathrm{g} / \mathrm{L}$. The most significant results regarding the aroma profile were determined for the wine from Avincis Dragasani vinery, where the climatic indicators ratio was optimum, thus conferring specific and quantifiable elements to the wine.
\end{abstract}

Keywords: GC-MS, oenological climate index, wine aroma compounds

\section{INTRODUCTION}

Natural factors have a great influence on the quality of grapes and wines, because the harvest of the same variety of grapes, transformed by the same winemaking technology provides wines of different quality if the

a National Research and Development Institute for Cryogenics and Isotopic Technologies ICSI Ramnicu Valcea, Romania; diana.stegarus@icsi.ro; oana.dinca@icsi.ro

b Lucian Blaga University of Sibiu, Faculty of Agricultural Sciences, Food Industry and Environmental Protection, Sibiu, Romania; ecaterina.lengyel@ulbsibiu.ro; daniela.sandru@ulbsibiu.ro

c Dunărea de Jos University of Galati, Faculty of Food Science and Engineering, Galati, Romania; petru.alexe@ugal.ro

d Lucian Blaga University of Sibiu, Faculty of Medicine, Sibiu, Romania; adina.frum@ulbsibiu.ro

Corresponding author: diana.stegarus@icsi.ro 
regions of the grapes' cultivation is different. These influences are currently being studied intensively, especially since there is a change in climate and, implicitly, the effects are major. Technological factors lead to obtaining quality, harmonious or specific wines. All the elements below are significant in the appreciation and cataloging of wines [1].

Climate is the main factor that conditions and determines the global spread of vines, being, through its elements, the most important natural factor. Through temperature, light, humidity, air movement, climate decisively influences the growth and fruiting of the vine, in fact it directly influences the physiological and biochemical processes [2]. The process of photosynthesis is influenced by temperature and light, and the rate of accumulation of sugars depends on the difference between the amount produced by photosynthesis and that consumed by respiration.

The vine is a light-loving plant, hence its classification among heliophilous plants. Within one hemisphere, both light and temperature decrease from the equator to the poles, but at the same time the aroma and sugars content of the grapes decrease, and the acidity registers an intense evolution. Too strong shade lowers the sugar content of grapes and promotes increased malic acid production and, climate change influences the growth and quality of vines [3].

In relation to its physical, chemical, and biological properties, the soil strongly influences the viticultural production and the quality of the grapes. It could be appreciated that the vine grows properly on forest soils, rendzinas, brown soils, alluvial soils and degraded chernozems. To the qualitative differences of the wines determined by the type of soil and the presence of limestone are added those determined by the texture of the soil. The most favorable texture of soil for growing vines is the clay - sandy one and the most favorable is clay [4].

In terms of altitude, famous vinicultural regions of the world are located between 80 and $150 \mathrm{~m}$ above sea level. However, there are vineyards that are located in mountainous areas at $1500 \mathrm{~m}$ altitude. In Romania, many vine plantations are located between 100 and 300 m altitude. If the plantations are at altitudes of approximately $167 \mathrm{~m}$, with an ideal exposure to the sun, slopes in a southerly and westerly direction, and a wide variety of soil types, from forest reddish brown to soils high in iron oxides or calcareous, they are appropriate for vine cultivation. Sun exposure is an important factor for sloping vineyards. Wines obtained from vine plantations that are organized in slopes are superior to those organized in plateaus $[5,6]$.

The mechanical composition of grapes is the gravimetric ratio between the constituent uvological units, clusters, skins, seeds, and pulp. The change in the chemical composition shows the influences on the technological 
process, especially on the chemical and organoleptic characteristics of the wine. Both mechanical and chemical composition are influenced by the nature of the soil, the degree of ripeness of the grapes, phytosanitary status, pedoclimatic conditions and agrotechnical processes applied $[7,8]$. Most of the grape flavors are transmitted to the wine, but because of the processes that take place through alcoholic fermentation, other new components appear, components that can lead to the wine's specific characteristics. Many flavors are found in small amounts in wines, but they confer the specificity of it. They accumulate under the beneficial action of the sun and proper soil or climatic factors, especially in young wines [9].

The aromatic differentiation of a wine obtained from the same grape variety can be achieved by sensorial methods, but more precisely by gaschromatographic methods, which have the possibility to highlight elements more precisely. The aroma of a wine is complex and depends on the concentrations of various compounds such as long-chain alcohols, esters, volatile fatty acids, lactones, phenolic compounds, and other essential compounds [10-13]. Studies show that one of the most cultivated grape varieties in Romania is Feteasca regala, the wines obtained from this cultivar present floral, citrus, or apricot notes. To potentiate some flavors, a series of pre-fermentative treatments can be used. Their role is to obtain finer, less acidic, or tastier wines [12,14-17].

Climate changes can lead to the differentiated accumulation of flavor compounds, and can influence the production of grapes, regardless of variety $[18,19]$.

The aim of this study is to identify and quantify the aroma compounds that are formed in Feteasca regala wine, under the influence of specific climatic factors. The wine samples were obtained in 2019 by using the same technological conditions and they came from three established wine centers in Romania.

\section{RESULTS AND DISCUSSION}

To provide a proper correlation between the aromatic profile of the analyzed wines and the geographic region from which they come from; a pedo-climatic characterization of those regions is mandatory. Thus, in the Samburesti region, the soils are mostly loamy, loamy-clayey, and clayeyloamy, a structure that influences the vine culture. These soils are characterized by a medium to weak supply of organic and mineral substances with a variable texture from loamy-sandy to clayey, with an important content of iron in the form of colloidal hydroxyl. The vine plantations are located on smooth slopes and plateaus with southern, south-eastern, and south-western exposure. 
The oenoclimatic aptitude index from 2019 was calculated at a value of 4568 , and the viticultural bioclimatic index reached 7.42.

The values for the climatic indexes were calculated by using the readings from the meteorological stations near to the viticultural centers. The analyzed parameters were temperature, solar radiation, and precipitations.

Irimia et al. (2014) established a series of suitability intervals for bioclimatic indexes and ecological factors for the temperate continental climatic conditions of Romania. The quantification was performed by using classes and points [20].

The bioclimatic index is representative for the winegrowing regions from the temperate continental climate areas. This index was calculated for the growing season (from April $1^{\text {st }}$ to September $30^{\text {th }}$ ). In order to obtain a high-quality white wine, the lbcv has to be between 5.1 and 13 . The formula used for the calculus was:

$$
\mathrm{lbcv}=\left(\mathrm{ASD} \cdot \Sigma \mathrm{t}_{\mathrm{a}} / \mathrm{PP} \cdot \mathrm{N}_{\mathrm{d}}\right) / 10
$$

where: Ibcv = bioclimatic index; ASD = actual sunshine duration, expressed as hours; $\Sigma \mathrm{t}_{\mathrm{a}}=$ the sum of daily average temperatures (greater than $10^{\circ} \mathrm{C}$ ); $\mathrm{PP}=$ precipitations, expressed as $\mathrm{mm}$ and $\mathrm{N}_{\mathrm{d}}=$ the number of days in the growing season [20].

The oenoclimate aptitude index (IAOe) shows the winemaking suitability, thus the optimum index is situated between 3790 and 4600 . The values that are greater than 4301 show the obtaining of high-quality white wines. This index was calculated for the growing season as well (from April $1^{\text {st }}$ to September $30^{\text {th }}$ ) by using the following formula:

$$
\mathrm{IAOe}=\mathrm{ASD}+\Sigma \mathrm{t}_{\mathrm{a}}-(\mathrm{PP}-250)
$$

where: $I A O e=$ oenoclimate aptitude index; $A S D=$ actual sunshine duration, expressed as hours; $\Sigma t_{a}=$ the sum of daily average temperatures (greater than $10^{\circ} \mathrm{C}$ ); $\mathrm{PP}=$ precipitations, expressed as $\mathrm{mm}$ and $250=$ the minimum precipitations required for vines that are not irrigated, expressed as $\mathrm{mm}$ [20].

In the Corcova region, the soils are reddish-brown with leached chernozems, medium texture, locally coarse or clayey-loamy. These types of soils have several advantageous physical and chemical characteristics for the cultivation of vines. The bottom soils are normal or slightly-moderately eroded on the slopes, followed by brown soils or weakly podzolite soils, moderately to strongly eroded on slopes and alluvial soils on the meadow terraces of Topolnita. The characteristic wines of this region are alcoholic wines, full-bodied, rich in extract and with a high content of mineral 
substances, these features being due to the existing soil types. The oenoclimatic aptitude index from 2019 was calculated at the value of 4532 , and the viticultural bioclimatic index reached 7.34.

In the Dragasani region, the vine plantations are located at altitudes exceeding $400 \mathrm{~m}$, with brown, forest reddish-brown soils, some of them are podzolites and rich in limestone and located on alluvial gravels. The dominant soils are luviosols and luvic brown soils which, together with the thermohydric conditions allow and recommend the cultivation of white grape varieties. The oenoclimatic aptitude index from 2019 was calculated at the value of 4596, and the viticultural bioclimatic index at 7.48 , which induces favorable climatic conditions for the vine culture.

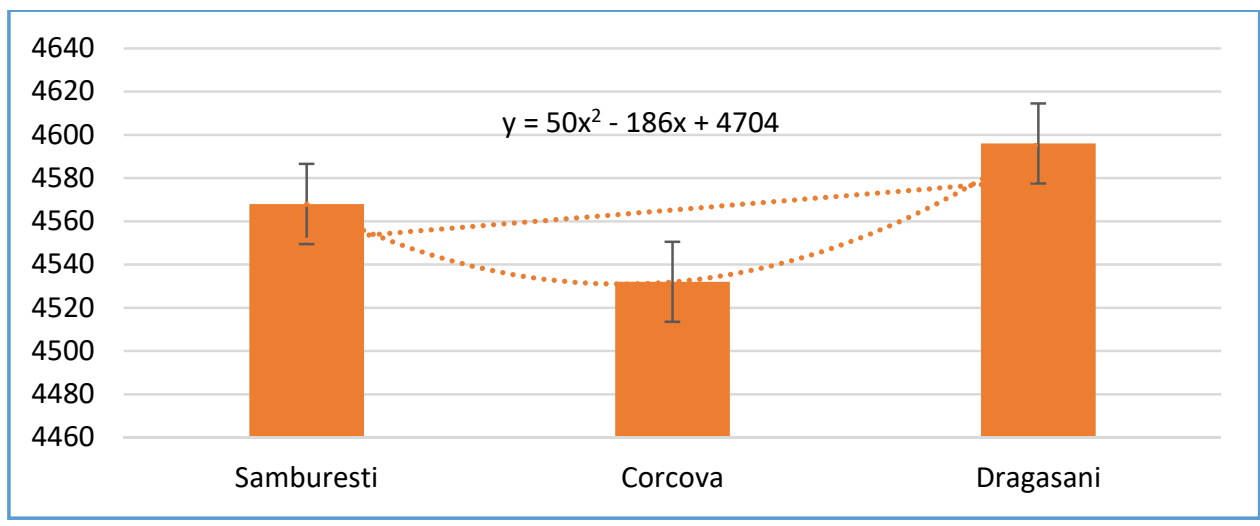

Figure 1. The oenoclimatic aptitude index calculated for the year 2019 for the investigated regions of origin of the Feteasca regala wine samples

Figures 1 and 2 show the differences between the three studied regions regarding the oenoclimatic aptitude index and the viticultural bioclimatic index. The highest values were registered in the Dragasani region and the lowest in the Corcova one, thus the flavors of the wines were influenced. 
DIANA IONELA STEGARUS, DANIELA SANDRU, PETRU ALEXE, ADINA FRUM, OANA BOTORAN, ECATERINA LENGYEL

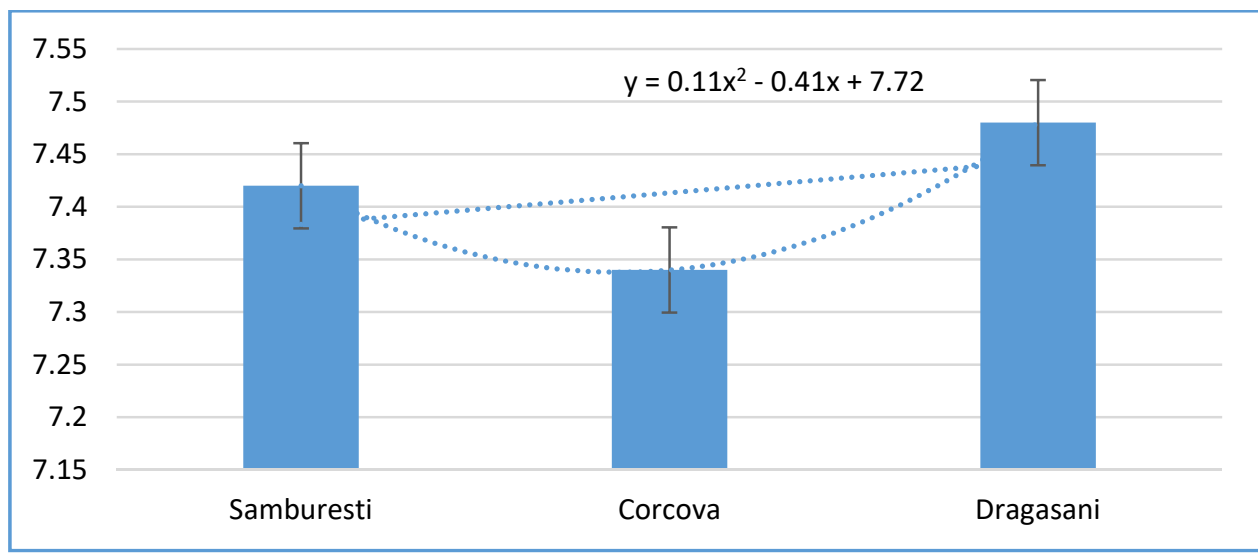

Figure 2. The viticultural bioclimatic index calculated for the year 2019 for the investigated regions of origin of the Feteasca regala wine samples

Table 1 shows the results obtained for the GC-MS analysis of the volatile aroma compounds of the wine samples in order to be able to correlate these results to the pedo-climatic indexes calculated.

Table 1. GC-MS analysis of volatile aroma compounds from the Feteasca regala wine samples

\begin{tabular}{|l|c|c|c|}
\hline \multirow{2}{*}{ Compounds } & \multicolumn{3}{c|}{ Feteasca regala wine samples ( $\boldsymbol{\mu g} / \mathbf{L})$} \\
\cline { 2 - 4 } & Samburesti & Corcova & $\begin{array}{c}\text { Avincis } \\
\text { Dragasani }\end{array}$ \\
\hline Alcohols & \multicolumn{3}{|c|}{} \\
\hline Iso butanol & 139.45 & 126.24 & 113.03 \\
\hline Butanol & 4.97 & 5.98 & 3.08 \\
\hline Isopentyl alcohol & 13214.01 & 12036.71 & 14001.15 \\
\hline 1-hexanol & 716.25 & 588.06 & 667.25 \\
\hline 4-methyl-1-pentanol & 0.00 & 1.02 & 0.62 \\
\hline E-3-hexenol & 14.36 & 10.66 & 12.12 \\
\hline Z-3-hexenol & 19.25 & 14.55 & 21.02 \\
\hline 2-nonanol & 9.05 & 12.18 & 16.07 \\
\hline 1-heptanol & 412.15 & 315.74 & 512.36 \\
\hline 2,3-butandiol & 1296.54 & 1406.36 & 874.24 \\
\hline 3-(methylthio)-1-propanol & 447.11 & 612.05 & 228.69 \\
\hline Linalool & 229.51 & 425.11 & 309.25 \\
\hline Terpineol & 99.36 & 129.27 & 202.14 \\
\hline 2-phenyl ethanol & 14355.20 & 12221.10 & 16214.50 \\
\hline
\end{tabular}




\begin{tabular}{|c|c|c|c|}
\hline \multirow[b]{2}{*}{ Compounds } & \multicolumn{3}{|c|}{ Feteasca regala wine samples $(\mu \mathrm{g} / \mathrm{L})$} \\
\hline & Samburesti & Corcova & $\begin{array}{c}\text { Avincis } \\
\text { Dragasani }\end{array}$ \\
\hline Trans-geraniol & 90.36 & 62.33 & 41.08 \\
\hline Glycerin & 836.06 & 508.51 & 615.47 \\
\hline Benzyl alcohol & 111.05 & 168.54 & 137.20 \\
\hline 3-hydroxy-butanone & 0.00 & 0.12 & 0.00 \\
\hline Total alcohols $(\mu \mathrm{g} / \mathrm{L})$ & 31994.68 & 28644.54 & 33969.27 \\
\hline \multicolumn{4}{|l|}{ Esters } \\
\hline N-amyl acetate & 10.25 & 6.25 & 14.36 \\
\hline Hexyl-acetate & 0.00 & 1.25 & 0.00 \\
\hline Ethyl caproate & 31.25 & 58.36 & 51.21 \\
\hline Ethyl lactate & 415.25 & 303.54 & 501.08 \\
\hline Ethyl octanoate & 98.56 & 215.71 & 166.52 \\
\hline Ethyl-3-hydroxy butyrate & 81.06 & 136.08 & 101.42 \\
\hline Ethyl decanoate & 88.21 & 102.37 & 96.95 \\
\hline Ethyl hydrogen succinate & 2355.19 & 5236.64 & 3021.14 \\
\hline Phenethyl acetate & 101.30 & 60.37 & 81.47 \\
\hline Diethyl malate & 114.67 & 155.54 & 184.20 \\
\hline Methyl-4-hydroxy-butanoate & 925.36 & 1625.14 & 1147.14 \\
\hline Total esters $(\mu g / L)$ & 4221.10 & 7901.254 & 5365.49 \\
\hline \multicolumn{4}{|l|}{ Fatty acids } \\
\hline Isobutyric acid & 92.25 & 74.14 & 51.69 \\
\hline Hexanoic acid & 847.54 & 1205.11 & 741.40 \\
\hline \multicolumn{4}{|l|}{ Fatty acids (continued) } \\
\hline Isovaleric acid & 100.28 & 141.79 & 168.73 \\
\hline Lactic acid & 315.41 & 197.57 & 229.54 \\
\hline Octanoic acid & 3215.41 & 1998.10 & 2318.19 \\
\hline Decanoic acid & 1005.51 & 1354.09 & 1208.11 \\
\hline Hexadecanoic acid & 91.25 & 101.47 & 74.54 \\
\hline Malic acid & 354.25 & 471.67 & 499.25 \\
\hline 2-oxoadipic acid & 23.25 & 13.47 & 19.54 \\
\hline Total fatty acids $(\mu g / L)$ & 6045.15 & 5557.41 & 5310.99 \\
\hline \multicolumn{4}{|l|}{ Lactones } \\
\hline Pantolactone & 51.23 & 29.15 & 34.66 \\
\hline Isovaniline & 22.15 & 11.09 & 14.14 \\
\hline Butyrolactone & 914.63 & 687.15 & 817.66 \\
\hline Total lactones $(\mu \mathrm{g} / \mathrm{L})$ & 988.01 & 727.39 & 866.46 \\
\hline Total volatiles $(\mu \mathrm{g} / \mathrm{L})$ & 43248.94 & 42830.59 & 45512.21 \\
\hline
\end{tabular}

Table 1 shows aroma compounds found in the analyzed samples. Long-chain alcohols, like isopentyl had concentrations between 12036.71 $\mu \mathrm{g} / \mathrm{L}$ for Feteasca regala wine from Corcova and $14001.15 \mu \mathrm{g} / \mathrm{L}$ for Avincis Dragasani. Isopentyl confers banana aromas to wines, caranda being a 
volatile cyanobacterial organic compound, and combined with other aroma compounds it contributes to the aroma palette of the wine. Terpenic alcohols (which give wines floral, fresh, and invigorating aromas) are present in the wine samples, like linalool with concentration between $229.51 \mu \mathrm{g} / \mathrm{L}$ for Samburesti region and $425.11 \mu \mathrm{g} / \mathrm{L}$ for Corcova region, terpineol with concentrations between $99.36 \mu \mathrm{g} / \mathrm{L}$ for Samburesti region and $202.14 \mu \mathrm{g} / \mathrm{L}$ for Dragasani region and trans-geraniol with concentrations between 41.08 $\mu \mathrm{g} / \mathrm{L}$ for Dragasani region and $90.36 \mu \mathrm{g} / \mathrm{L}$ for Samburesti region. 4-methyl-1pentanol (which gives wines a walnut aroma) was not detected in the Samburesti region wine sample, instead $1.02 \mu \mathrm{g} / \mathrm{L}$ was quantified in the one from the Corcova region and $0.62 \mu \mathrm{g} / \mathrm{L}$ in the one from the Dragasani region. Glycerin gives the wines sweetness and velvety properties, being found in the analyzed samples in amounts of $836.06 \mu \mathrm{g} / \mathrm{L}$ for the Samburesti region sample, $508.50 \mu \mathrm{g} / \mathrm{L}$ for the Corcova region sample and $615.47 \mu \mathrm{g} / \mathrm{L}$ for the Dragasani region sample. The results obtained are consistent to the values provided by specialists in the field for the wines to be balanced and harmonious [6]. Significant amounts of 2-phenyl-ethanol were identified in the wine samples, the results were between $12221.10 \mu \mathrm{g} / \mathrm{L}$ for the Corcova region sample and $16214.50 \mu \mathrm{g} / \mathrm{L}$ for the Dragasani region sample. This compound participates in the aromatic palette of the wine through the floral notes conferred, being present in all the assortments of wines in significant quantities. 3-hydroxy-butanone is a compound that results from the alcoholic fermentation of must under the influence of Saccharomyces wine yeasts and gives butter aroma to wines. In the wine samples, this compound was present only in the one from Corcova region with an amount of $0.12 \mu \mathrm{g} / \mathrm{L}$. This amount does not lead to imbalances in the wine's aromatic palette.

Figure 3 shows the evolution of the total long-chain alcohols in the wine samples analyzed. The highest values were recorded for the wine sample from the Dragasani region (33969.27 $\mu \mathrm{g} / \mathrm{L})$, followed by the one from the Samburesti region $(31994.68 \mu \mathrm{g} / \mathrm{L})$ and the lowest value was recorded for the sample from the Corcova region $(28644.54 \mu \mathrm{g} / \mathrm{L})$.

Esters are valuable compounds for wines, as they play an important role in their aromatic palette. Thus, fruit aromas as banana are conferred by the presence of the $\mathrm{N}$-amyl acetate, which was quantified in the samples analyzed at $10.25 \mu \mathrm{g} / \mathrm{L}$ in the wine from the Samburesti region, $6.25 \mu \mathrm{g} / \mathrm{L}$ for the one from the Corcova region and $14.36 \mu \mathrm{g} / \mathrm{L}$ for the one from the Dragasani region. Hexyl acetate was not detected in the samples from the Samburesti and Dragasani regions and a low quantity was determined for the sample from the Corcova region $(1.25 \mu \mathrm{g} / \mathrm{L})$. This compound leads to aromas of green apple and sweet cherries. These aromas were not found in 
the wine samples analyzed. Ethyl caproate constitutes a valuable compound if found in wines because of the fruity aroma of pineapple that it confers to wines and combined with other esters they provide a harmonious and pleasant aroma to wines. This compound was quantified for the wine samples analyzed at $31.25 \mu \mathrm{g} / \mathrm{L}$ for the wine from the Samburesti region, $58.36 \mu \mathrm{g} / \mathrm{L}$ for the one from the Corcova region and $51.21 \mu \mathrm{g} / \mathrm{L}$ for the one from the Dragasani region.

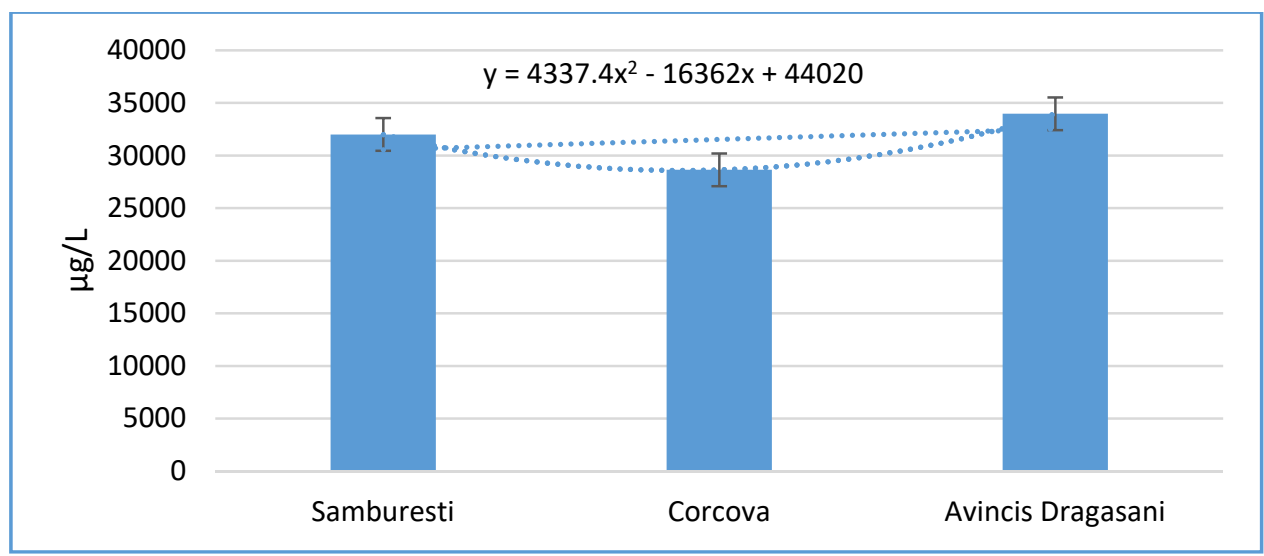

Figure 3. The variation of the total long-chain alcohols from the wine samples analyzed

Ethyl lactate is an ester that exists in every wine. It confers sweet or buttery, fruity, creamy, or rum aromas to wines. The analyzed wine samples had $303.54 \mu \mathrm{g} / \mathrm{L}$ for the wine from the Corcova region, $501.08 \mu \mathrm{g} / \mathrm{L}$ from the one from the Dragasani region and $415.25 \mu \mathrm{g} / \mathrm{L}$ for the one from the Samburesti region. Ethyl hydrogen succinate is an ester that confers fruity melon aromas. It was quantified at $2355.19 \mu \mathrm{g} / \mathrm{L}$ for the wine from the Samburesti region, $5236.64 \mu \mathrm{g} / \mathrm{L}$ for the one from the Corcova region and $3021.14 \mu \mathrm{g} / \mathrm{L}$ for the one from the Dragasani region. Significant differences were observed between the analyzed wine samples from the three regions, regarding this compound.

Other esters such as ethyl octanoate or ethyl decanoate contribute to the aromatic palette of the wine giving it fruity or sweet notes, in even larger amounts of soap. The amounts determined for these compounds are similar to the ones listed in literature [9]. Figure 4 shows the amounts of total esters determined for the wine samples analyzed. $4221.10 \mu \mathrm{g} / \mathrm{L}$ were determined for the wine sample from the Samburesti region, $7901.25 \mu \mathrm{g} / \mathrm{L}$ for the one from the Corcova region and $5365.49 \mu \mathrm{g} / \mathrm{L}$ for the one from the Dragasani region. 
DIANA IONELA STEGARUS, DANIELA SANDRU, PETRU ALEXE, ADINA FRUM, OANA BOTORAN, ECATERINA LENGYEL

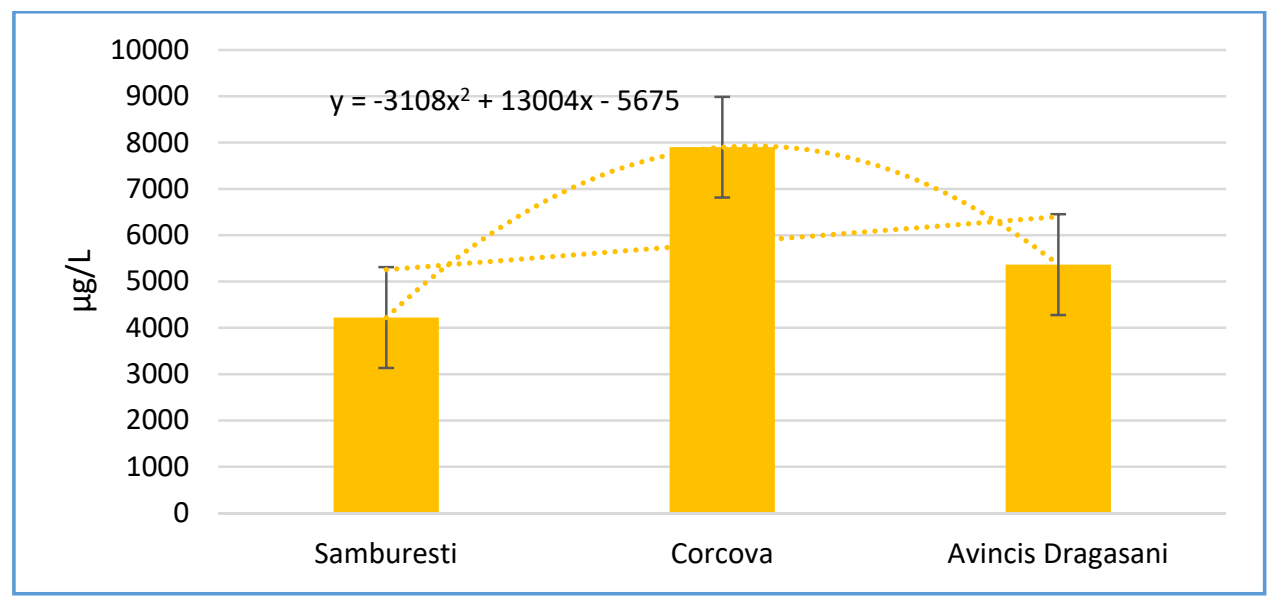

Figure 4. The variation of the total esters from the wine samples analyzed

Fatty acids participate along with the other volatile compounds in completing the aromatic palette of wines. Although the aromas conferred by volatile fatty acids tend to be in less pleasant areas (rancid, sour, cheesy, greasy, even mold), in small amounts they have a decisive role in the formation of the sensory properties of wines. Certain compounds confer hints of sweat, hot, sour, or harsh which led to a complex aromatic profile. In the Feteasca regala wine samples, a series of volatile fatty acids were quantified, such as isobutyric acid with values of $92.85 \mu \mathrm{g} / \mathrm{L}$ for the Samburesti area, $74.14 \mu \mathrm{g} / \mathrm{L}$ for the Corcova area and $51.69 \mu \mathrm{g} / \mathrm{L}$ for the Dragasani area. These compounds give the acidic aroma of the wines. The isovaleric acid (3methylbutanoic acid) gives a sweat and cheese odor was identified in the analyzed samples in amounts starting from $100.28 \mu \mathrm{g} / \mathrm{L}$ for the Samburesti region and reaches $168.73 \mu \mathrm{g} / \mathrm{L}$ for the Dragasani region. The octanoic and decanoic acids that give an odor of sweat or harsh showed significantly higher amounts reaching maximum values of $3215.41 \mu \mathrm{g} / \mathrm{L}$ in the wine from the Samburesti region and $1354.09 \mu \mathrm{g} / \mathrm{L}$ in the wine from the Corcova region. Lactic and malic acids lead to the adjustment of the unpleasant aromas given by volatile fatty acids so that their presence is considered beneficial to the aromatic palette of wines. The values obtained were at a maximum amount of $315.41 \mu \mathrm{g} / \mathrm{L}$ in the wine from the Samburesti region and respectively $499.25 \mu \mathrm{g} / \mathrm{L}$ in the one from the Dragasani region.

Figure 5 shows the total of the fatty acids identified and quantified in the Feteasca regala wine samples. $6045.15 \mu \mathrm{g} / \mathrm{L}$ were determined for the wine from the Samburesti area, $5557.41 \mu \mathrm{g} / \mathrm{L}$ for the one from the Corcova region and $5310.99 \mu \mathrm{g} / \mathrm{L}$ for the one from the Dragasani region. 
THE INFLUENCE OF CLIMATIC FACTORS ON THE AROMA COMPOUNDS ...

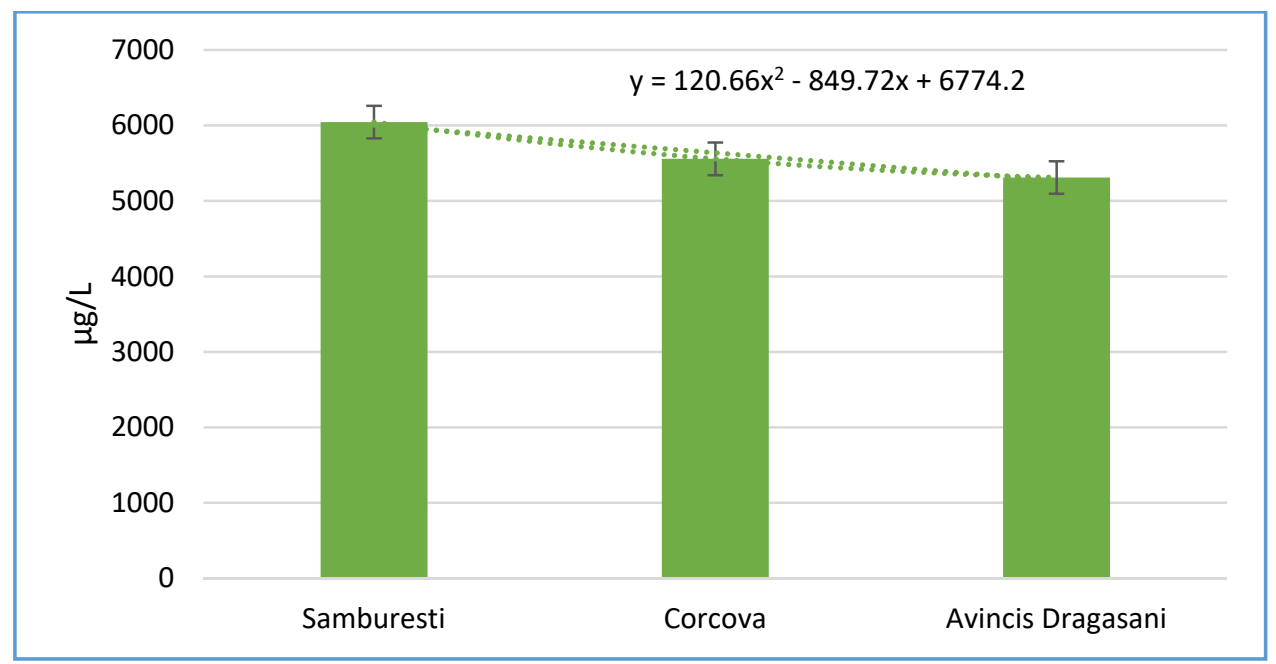

Figure 5. The variation of the total fatty acids from the wine samples analyzed

Lactones have an important role in completing the odorizing palette of wines. The aromas are sugar cotton wool (pantolactone) and caramel (butyrolactone). The amounts identified were $988.01 \mu \mathrm{g} / \mathrm{L}$ for the Samburesti region, $727.39 \mu \mathrm{g} / \mathrm{L}$ for the Corcova region and $866.46 \mu \mathrm{g} / \mathrm{L}$ for the Dragasani as can be observed in figure 6 .

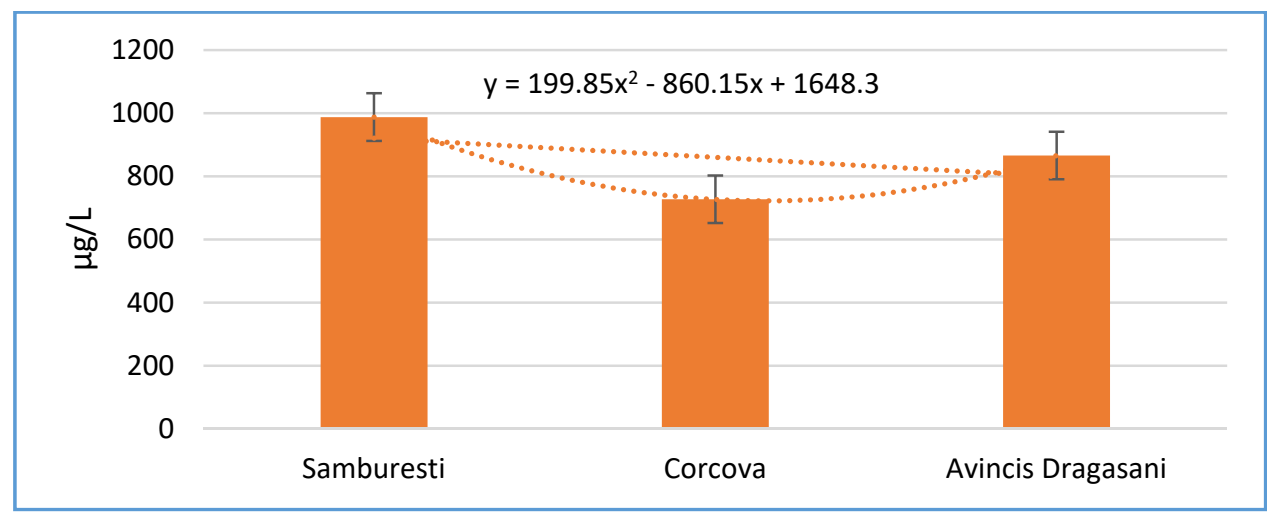

Figure 6. The variation of the total lactones from the wine samples analyzed 
The total volatile compounds determined from the Feteasca regala wines analyzed led to the differentiation of the wines even though the parameters and technological processes used for their manufacturing were similar. Figure 7 shows that the highest quantity of total volatile compounds was registered for the Dragasani region wine with $45512.21 \mu \mathrm{g} / \mathrm{L}$, followed by the Samburesti region with $43248.94 \mu \mathrm{g} / \mathrm{L}$ and then Corcova region with $42830.59 \mu \mathrm{g} / \mathrm{L}$.

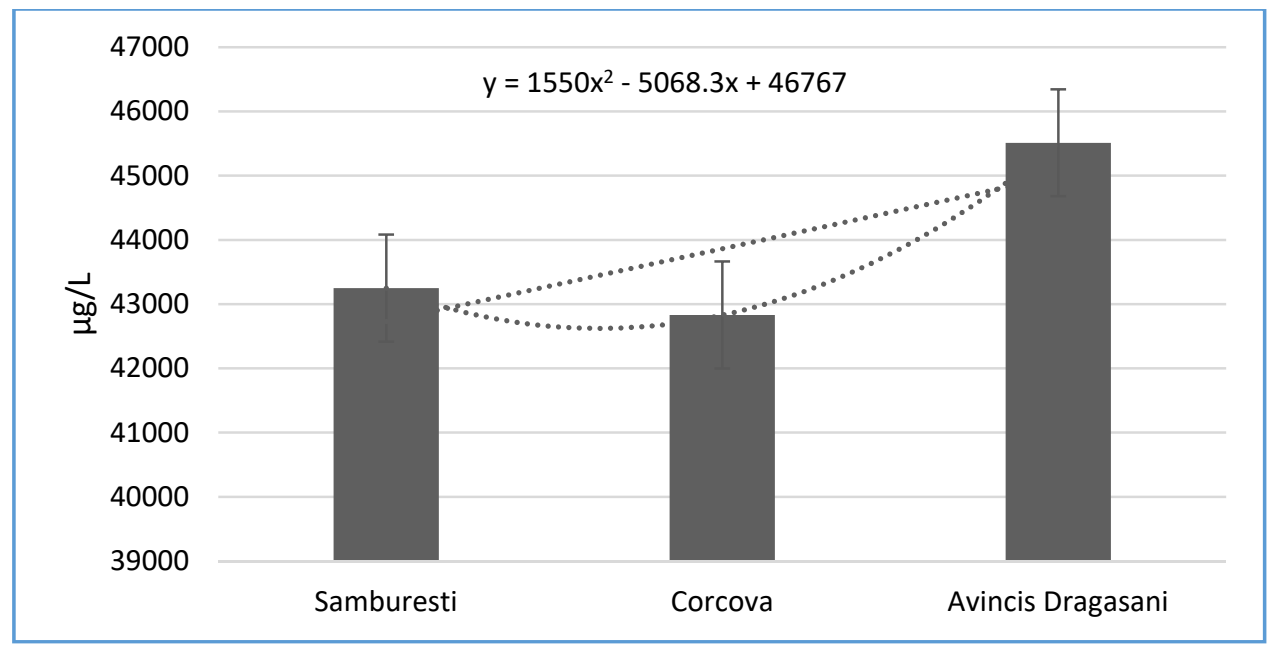

Figure 7. The variation of the total volatile compounds from the wine samples analyzed

PCA was applied to the matrix formed by the total minor volatile compounds corresponding to all of the different wine samples. The maximum number of PCs was set at three; however, the first two components explained the data variance $(63.2 \%$ and $36.8 \%)$, as shown in the score plot in figure 8 . The PCA score plots of evaluated volatile compounds showed the best separation of points for Feteasca Regala wine originating from three different vineyards located in the same area. 


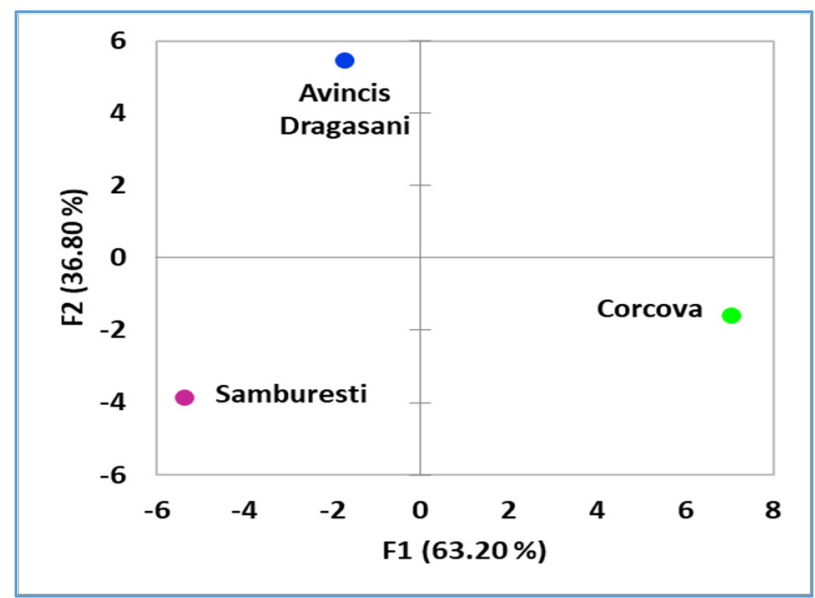

Figure 8. PCA score plot of the total minor compounds by geographical origin of Feteasca Regala wine

The separation between Samburesti and Avincis Dragasani can be seen through the second principal component (PC2), which describes $36.8 \%$ of the total variance. The PCA loadings showed that iso butanol, 2-nonanol, terpineol, trans-geraniol, 2,3-butandiol, isobutyric acid and isovaleric acid had the highest role in the formation of PC2. The majority of these volatile compound belong to the alcohols group. Corcova region was separated from the other two through the first principal component (PC1), consisting of esters and fatty acids. PCA represents one of the most versatile of all chemometric techniques that involves data dimensionality reduction by mathematical modelling using a covariance analysis between factors and exploring the hidden trends in a data matrix without much loss of information [21]. Even though the results obtained from the PCA revealed obvious clustering of the samples according to their provenance, which indicated differences in Feteasca Regala wine samples composition, and was in fact mostly coherent with the previously explained results. For a more precise determination regarding variables contribution, in the next part, we reduced the measurement to most relevant factors by applying Kaiser-Meyer-Olkin measure of sampling adequacy to assess which of the data were the most suitable for PCA at an accepted level of significance of $\alpha=0.60$. The goal was to reduce the number of items by finding correlations between them and abstracting a smaller number of factors (figure 9). 


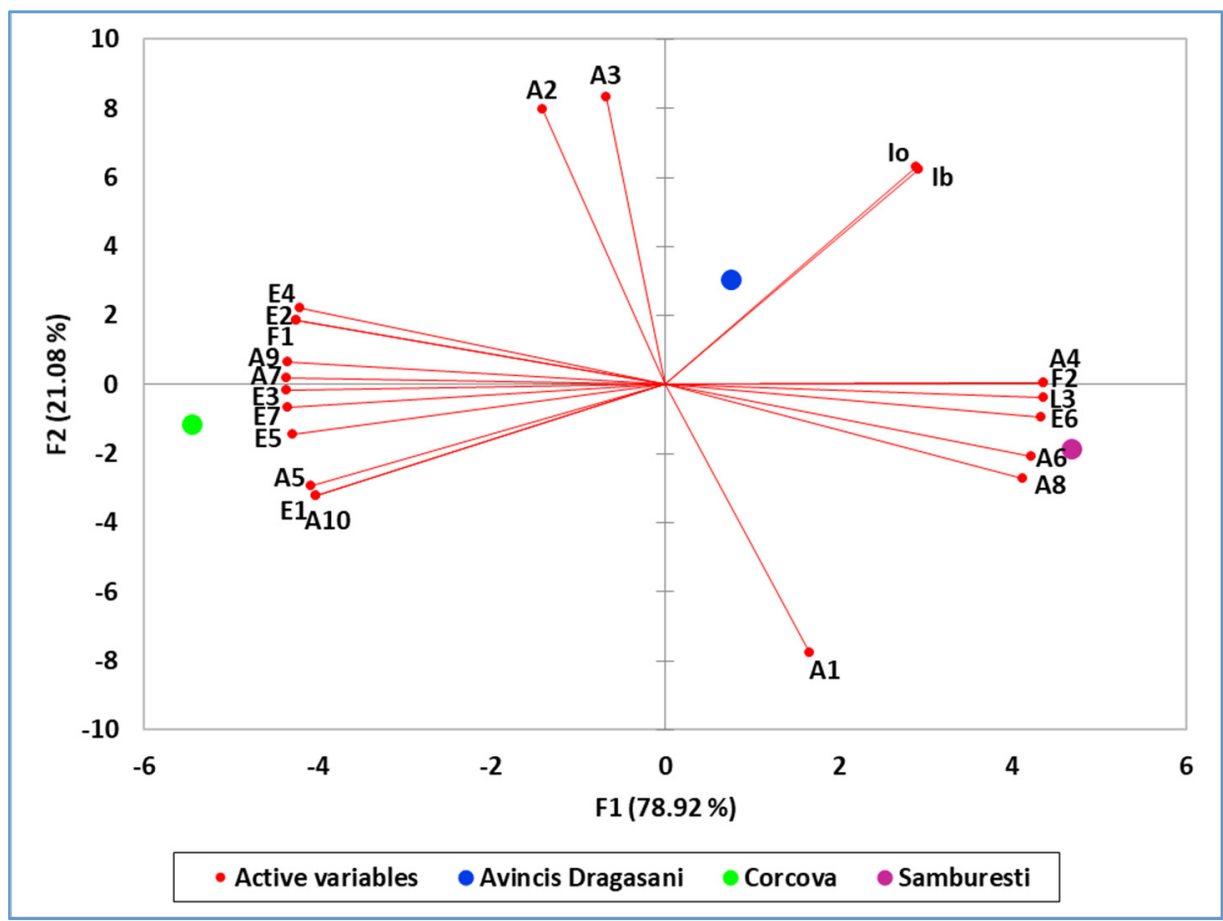

Figure 9. PCA score plot using Kaiser-Meyer-Olkin determined variables at an accepted level of significance of $\alpha=0.60$ (lo - oenoclimatic aptitude index; lb viticultural bioclimatic index; A1 - iso butanol; A2 - 2-nonanol; A3 - Terpineol; A4 - 1-Hexanol; A5 - 4-methyl-1-pentanol; A6 - E-3-hexenol; A7 - Linalool; A8 - Glycerin; A9 - Benzyl alcohol; A10 - 3-hydroxy-butanone; E1 - Hexylacetate; E2 - Ethyl octanoate; E3 - Ethyl-3-hydroxy butyrate; E4 - Ethyl decanoate; E5 - Ethyl hydrogen succinate; E6 - Phenethyl acetate; E7 Methyl-4-hydroxy-butanoate; F1 - Decanoic acid; F2 - 2-Oxoadipic acid and L3 - Butyrolactone)

After considering the Kaiser-Meyer-Olkin selected components, the performed PCA analysis revealed that the first two components explained $100 \%$ of the total variation. The first principal component (PC1) explained $78.9 \%$ of the total variance and presented a high negative correlation with most of the ester group, separating Samburesti region from Corcova. PC2 explained $21.1 \%$ of the total variance and separated Avincis Dragasani area from the other and mostly corresponded to the oenoclimatic aptitude index and viticultural bioclimatic index. Multivariate statistical methods were essentially useful to reduce a large number of correlated variables into a small 
number of uncorrelated vectors, allowing a clearer graphical representation. Therefore, the attempt to eliminate the elements to define better the variables responsible for origin separation was made, but the percentage of explained variance remained the same. The wine volatile profile and climatic factors along with chemometric analysis methods successfully differentiate the geographical locations. Even if the provenance regions were close in distance, each of them has their own particularities in terms on pedoclimate offering to the same variety unique features.

\section{CONCLUSIONS}

Following the evaluation of aroma compounds in the wine samples analyzed, the highest amounts were determined for wines obtained from grapes harvested from vineyards that were situated on brown or brownreddish soils, rich in limestone and located on alluvial gravels, where the oenoclimatic aptitude index and the viticultural bioclimatic index were high. This was possible in the Dragasani region, the results obtained being superior to those in Samburesti and Corcova regions. These indicators have led to a more significant accumulation of long-chain alcohols. A slightly lower pedoclimatic index was reported in the Samburesti region where aroma compounds such as long-chain alcohols and esters showed amounts below those of Dragasani region. These values can also be influenced by soils that have a different configuration: clayey, loamy-clayey. Instead, crops that are oriented on the southern, south-eastern, and south-western slopes lead to the accumulation of volatile compounds such as fatty acids and lactones at significantly higher values than Dragasani and Corcova regions. The lowest values of the calculated climatic indexes were in the Corcova region (about $10-12 \%)$, although the soil has favorable properties for growing vines (reddish-brown with leached chernozems, medium texture, locally coarse or clay-loam). These qualities have led to wines with a rich ester content which gives them specific aromas and bouquet.

In perspective of the outcomes achieved inside this preliminary investigation, it can be concluded that a classification approach based on the combination of volatile compounds and climatic factors, together with appropriate chemometric techniques is a promising and effective way for differentiating Feteasca regala wine variety conforming to their geographical origin. The analyzed wines surprised only a segment of the multitude of factors that lead to the formation of the aromatic palette of a wine, but as it is observed for the same variety volatile compounds can accumulate in variable amounts contributing to the formation of their sensory properties. 


\section{EXPERIMENTAL SECTION}

The samples analyzed were 2019 production Feteasca regala wines from three wine centers from Romania, Valcea county, namely: Samburesti $\left(44^{\circ} 48^{\prime} \mathrm{N} 24^{\circ} 23^{\prime} \mathrm{E}\right)$, Corcova $\left(44^{\circ} 41^{\prime} \mathrm{N} 23^{\circ} \mathrm{E}\right)$ and Avincis Dragasani $\left(44^{\circ} 39^{\prime}\right.$ $\left.\mathrm{N} 24^{\circ} 15^{\prime} \mathrm{E}\right)$ as illustrated in figure 10.

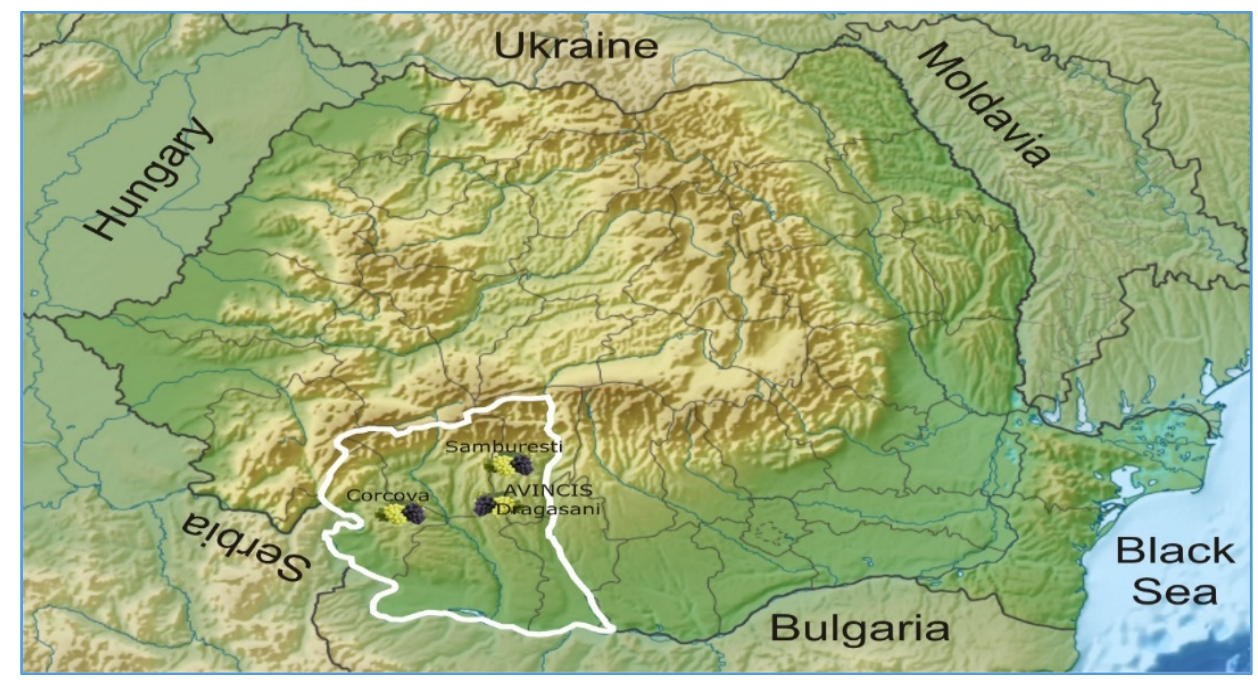

Figure 10. The representation of the studied wine centers from Romania

\section{Reagents}

All the reagents used were analytical grade. Isobutanol $95 \%$, butanol 98\%, isopentyl alcohol 98\%, 1-hexanol, 4-methyl-1-pentanol 99\%, E-3hexenol, Z-3-hexenol 98\%, 2-nonanol, 1-heptanol, 2,3-butanediol 99\%, 3(methylthio)-1-propanol 97\%, linalool, terpineol 98\%, 2-phenyl ethanol, trans-geraniol, glycerin, benzyl alcohol, 3-hydroxy-butanone 98\%, $\mathrm{N}$-amyl acetate, hexyl-acetate $97 \%$, ethyl caproate, ethyl lactate, ethyl octanoate $98 \%$, ethyl-3-hydroxy butyrate, ethyl decanoate $99 \%$, ethyl hydrogen succinate, phenethyl acetate, diethyl malate, methyl-4-hydroxy-butanoate $97 \%$, isobutyric acid, hexanoic acid $99 \%$, isovaleric acid $98 \%$, lactic acid $99 \%$, octanoic acid, decanoic acid $99 \%$, hexadecanoic acid $97 \%$, malic acid $95 \%$, 2-oxoadipic acid 97\%, pantolactone 98\%, isovaniline 95\%, butyrolactone $97 \%$, methylene chloride and sodium sulfate were purchased from Sigma-Aldrich, (Milwaukee, WI, SUA) and Fluka (Buchs, Switzerland). 


\section{Sample preparation}

$100 \mathrm{~mL}$ of wine sample were extracted 3 times with dichloromethane $(10 \mathrm{~mL}, 10 \mathrm{~mL}$, and $5 \mathrm{~mL}$ ) for 15 minutes at $700 \mathrm{rpm}$. The organic extract was dried on anhydrous sodium sulfate, concentrated up to $1.0 \mathrm{~mL}$ and analyzed.

The samples were collected from three different bottles for each wine and the analysis was performed in triplicate for each sample collected. The results were expressed as the average of all determinations performed for the same type of sample.

\section{GC-MS analysis}

The analysis of the minor volatile compounds from the wine samples was performed by using a gas chromatograph (GC) coupled with a mass spectrometer (MS) Varian 450-GC with Varian 240-MS equipment. The GC was equipped with a Thermo Scientific TG-WAXMS $(60 \mathrm{~m} \times 0,32 \mathrm{~mm}$, $0,25 \mu \mathrm{m}$ film thickness) capillary column. The carrier gas was helium at a flow of $1.2 \mathrm{~mL} / \mathrm{min}$ and a splitting injection system was used. The injection volume was $1 \mu \mathrm{L}$. The column temperature was programed as follows: $35^{\circ} \mathrm{C}$ for 2.8 min., then it increases up to $120^{\circ} \mathrm{C}$ with $4^{\circ} \mathrm{C} / \mathrm{min}$. for $4 \mathrm{~min}$., ramped up to $190^{\circ} \mathrm{C}$ with $10^{\circ} \mathrm{C} / \mathrm{min}$. maintained for $7 \mathrm{~min}$. The mass detector was used at $70 \mathrm{eV}$ in the scan mode, and the mass range for ion scan was between 40 and $300 \mathrm{~m} / \mathrm{z}$ (mass to charge ratio).

The analysis of the volatile compounds was done by comparing the relative retention times and mass fragmentation of each compound from the sample chromatogram to the chromatograms that show compounds analyzed by using standard solutions and by comparison to the spectral library (NIST Mass Spectral Library 08) as well.

\section{Statistical analysis}

The primary aim of the chemometric evaluation was to show the relationship between the wine samples and the minor volatile compounds in order to generate a visual plot of the samples and their distribution on a score plot and interpret their trends. To process the minor volatile compounds from the wine samples, PCA (principal component analysis) was applied [22]. Principal component analysis was selected because of its capability to explore and model experimental data, assess variable significance and correlations, and create simple bidimensional plots in which the wine samples (also known as objects) and the minor volatile compounds are visualized (scores plot and loadings plot, respectively). In order to use the appropriate statistical 
DIANA IONELA STEGARUS, DANIELA SANDRU, PETRU ALEXE, ADINA FRUM, OANA BOTORAN, ECATERINA LENGYEL

tests for PCA, it was first necessary to reduce the measurement to most relevant factors. For this purpose, Kaiser-Meyer-Olkin measure of sampling adequacy was used to assess which data are suitable for PCA s for the accepted level of significance $\alpha=0.60$. The goal was to reduce the number of items by finding correlations between them and abstracting a smaller number of factors. During statistical evaluation of the data, Microsoft Excel 2016 was used for the descriptive statistics, while XLSTAT Addinsoft 2014.5.03 version (Addinsoft Inc., USA) software was used for the chemometrical evaluation of the results.

\section{ACKNOWLEDGMENTS}

This work is supported by the project ANTREPRENORDOC, in the framework of Human Resources Development Operational Programme 2014- 2020, financed from the European Social Fund under the contract number 36355/23.05.2019 HRD OP /380/6/13 - SMIS Code: 123847.

\section{REFERENCES}

1. R. Baumes R.; Wine Aroma Precursors, Wine Chemistry and Biochemistry, Springer, New York, 2009, pp. 251-265

2. I. Rebenciuc; O. Tița; Management of Sustainable Development, 2019, 11 (2), 59-64

3. L.M. Irimia; C.V. Patriche; B. Roșca; Theor. Appl. Climatol., 2018, 133, 1-14

4. R.R. Walker; D.H. Blackmore; P.R. Clingeleffer; Aust. J. Grape Wine R., 2010, 16(1), 243-257

5. A. Dobrei; M. Mălăescu; A. Ghiță; T. Cristea; A. Drăgunescu; J Hortic, Forestry and Biotechnology, 2010, 14(1), 298-301

6. I. Rebenciuc; Vinurile moldovenești - aromă și savoare, Editura Universitatii Lucian Blaga din Sibiu, 2020

7. N. Pomohaci; V.V. Cotea; V. Stoian; I. Nămoloşanu; Oenology, Ceres, Bucharest, 2001

8. H.A. Gomez-Gomez; I.O. Minatel; C.V. Borges; M. Ortiz Mayo Marques; E. Tadeu da Silva; G.C. Monteiro; M.J.R. da Silva; M.A. Tecchio; G.P. Pereira Lima; J. Agr. Sci., 2018, 10(12), 65-77

9. L. Louw; A. Tredoux; P. Van Rensburg; M. Kidd; T. Naes; H. Nieuwoudt; S. Afr. J. Enol. Vitic., 2016, 31(2), 213-225

10. C. González-Barreiro; R. Rial-Otero; B. Cancho-Grande; J. Simal-Gándara; 2013, Crit. Rev. Food Sci., 2013, 55(2), 202-218

11. D.I. Popescu; Repere analitice in autentificarea vinurilor românești, Editura Universitatii Lucian Blaga din Sibiu, 2019 
12. I.S. Pretorius; P.B. HØj; Aust. J. Grape Wine R., 2005, 11(12), 83-108

13. I. Rebenciuc; O. Tița; D.I. Popescu; Manag Sustain Dev, 2019, 11(2), 55-58

14. A.M. Moroșanu; C.E. Luchian; M. Niculaua; C.L. Colibaba; A.C. Tarțian; V.V. Cotea; Not. Bot. Horti. Agrobo., 2018, 46(1), 247-259

15. J.H. Swiegers; R. Willmott; A. Hill-Ling; D.L. Capone; K.H. Pardon; G.M. Elsey; K.S. Howell; M.A. de Barros Lopes; M.A. Sefton; M. Lilly; I.S. Pretorius; Dev. Food Sci., 2006, 43, 113-116

16. A.G. Reynolds; J. Schlosser; D. Sorokowsky; R. Roberts; J. Willwerth; C. de Savigny; Am. J. Enol. Vitic., 2007, 58, 25-41

17. I. Rebenciuc; O. Tița; Bulletin UASVM Animal Science and Biotechnologies, 2018, 75(1)

18. A. Popa; G. Condei; D. Popa; F. Dragomir; M. Seiculescu; M. Nica; C. Genoiu; A. Dunoiu; Buletin USAMV-CN, 2006, 63

19. A. Popescu; V. Enache; C. Simion; A. Donici; G. Tabaranu; 2009, Bulletin UASVM, 2009, 66(1)

20. L.M. Irimia; C.V. Patriche; H. Quenol; J Int Sci Vigne Vin, 2014 48(3),145-167

21. H. Kaygusuz; F. Tezcan; F.B. Erim; O. Yildiz; H. Sahin; Z. Can; S. Kolayli; LWT -Food Sci. Tech., 2016, 68, 273-279

22. M. Gajek; A. Pawlaczyk; M.I. Szynkowska-Jozwik; Molecules, 2021, 26, 214 
